\title{
As vozes de alunos do ensino médio acerca do ensino remoto emergencial: possibilidades e desafios na aprendizagem
}

The voices of high school students about emergency remote teaching: possibilities and challenges in learning

Las voces de los estudiantes de la escuela secundaria sobre la enseñanza remota de emergencia: posibilidades y retos en el aprendizaje

\section{Resumo}

A pandemia do novo Coronavírus (COVID-19) provocou uma série de mudanças em todo o mundo. A educação teve que se readequar para atender todos os alunos de todos os níveis de ensino. No entanto, problemas foram evidenciados sobre diversos aspectos, principalmente pela baixa acessibilidade dos estudantes. Assim, compreender a visão dos alunos em relação ao Ensino Remoto Emergencial (ERE) é de suma importância para a melhor readequação das aulas, considerando que milhões de alunos no Brasil não possuem infraestrutura básica como computador e internet, para continuarem as aulas pelo ERE. Nesse sentido, esta pesquisa teve como objetivo identificar as possibilidades e desafios na aprendizagem de estudantes do ensino médio no ERE. No processo metodológico desta investigação de abordagem qualitativa, utilizou-se um questionário aplicado via Google Forms, com os discentes de um colégio estadual. Os resultados sinalizam como possibilidades, a continuidade dos estudos, poder estudar em casa e flexibilização de horário; a ausência de contato físico e diálogo com os professores, provocaram dificuldades de aprendizagem como consequência.

Palavras-chave: Diagnóstico escolar; Ensino-aprendizagem; Ensino médio.

\begin{abstract}
The pandemic of the new Coronavirus (COVID-19) has brought about a series of changes around the world. Education had to readjust to serve all students at all levels of education. However, problems were evidenced on several aspects, mainly due to the low accessibility of the students. Thus, understanding the students' view of Emergency Remote Education (ERE) is of paramount importance for the better readjustment of classes, considering that millions of students in Brazil do not have basic infrastructure like computer and internet, to continue classes through ERE. In this sense, this research aimed to identify the possibilities and challenges in the learning of high school students at ERE. In the methodological process of this investigation with a qualitative approach, a questionnaire applied via Google Forms was used, with the students of a state school. The results indicate as possibilities, the continuity of studies, being able to
\end{abstract}


study at home and flexible hours; the absence of physical contact and dialogue with teachers, caused learning difficulties as a consequence.

Keywords: School diagnosis; Teaching-learning; High school.

\section{Resumen}

La pandemia del nuevo Coronavirus (COVID-19) ha provocado una serie de cambios en todo el mundo. La educación tuvo que reajustarse para atender a todos los estudiantes en todos los niveles educativos. Sin embargo, se evidenciaron problemas en varios aspectos, principalmente debido a la baja accesibilidad de los estudiantes. Por lo tanto, comprender la visión de los estudiantes sobre la Educación Remota de Emergencia (ERE) es de suma importancia para el mejor reajuste de las clases, considerando que millones de estudiantes en Brasil no cuentan con infraestructura básica como computadora e internet, para continuar las clases a través de ERE. En este sentido, esta investigación tuvo como objetivo identificar las posibilidades y desafíos en el aprendizaje de los estudiantes de secundaria en ERE. En el proceso metodológico de esta investigación con enfoque cualitativo, se utilizó un cuestionario aplicado vía Google Forms, con los alumnos de una escuela pública. Los resultados indican como posibilidades, la continuidad de los estudios, poder estudiar en casa y horarios flexibles; la ausencia de contacto físico y diálogo con los profesores, provocó dificultades de aprendizaje como consecuencia.

Palabras clave: Diagnóstico escolar; Enseñanza-aprendizaje; Escuela secundaria.

\section{Introdução}

Esta investigação teve como objetivo identificar os possibilidades e desafios na aprendizagem de estudantes do ensino médio no REANP (Regime Especial de Aulas Não-Presenciais), ofertado pelo Colégio Estadual da Polícia Militar de Goiás Unidade "Carlos Cunha Filho".

O início da pandemia da COVID-19 causou um grande impacto na educação em todo o mundo, levando a uma readequação no ensino. As Tecnologias Digitais da Informação e Comunicação (TDIC) desempenharam um papel importante para com a continuidade das aulas de forma remota. O Ensino Remoto Emergencial (ERE) começou a ser utilizado em todo o Brasil, sendo um modo alternativo de ensino devido às circunstâncias de crise. O ERE objetiva a disponibilização temporária aos conteúdos curriculares que antes eram cumpridos de forma presencial (Rondini et al. 2020). No entanto, diante da rapidez no remanejamento das aulas paro o ERE, foram evidenciados diversos problemas como o despreparo ou preparação superficial dos professores com as TDICs (Cristina, 2020), além da falta de acessibilidade a equipamentos e internet de qualidade para as aulas virtuais; assim como a formação docente pouco adequada pode influenciar diretamente na utilização das tecnologias essenciais.

Os estudantes inseridos no ERE foram afetados de diversas maneiras do ponto de vista de seu aprendizado, com destaque a falta de acesso tecnológico, desenvolvimento de transtornos psiquiátricos, como ansiedade e depressão, problemas familiares e, sobretudo pela falta de contato social, provocado pelo distanciamento físico e social (Médici et al. 2020; Alves et al. 2020). Desta forma, os discentes apresentam dificuldades para se adaptar e acompanhar as aulas; consequentemente, prejudicando a resolução de atividades, formação de bagagem teórica, além de inviabilizar e dificultar a participação deles em vestibulares e no Exame Nacional do Ensino Médio (ENEM), pois se auto titulam como impasses para isto (Médici et al. 2020; Alves et al. 2020).

Os professores, por sua vez, enfrentam uma série de dificuldades, tendo em vista a adaptação entre as TDICs como ferramentas primárias de ensino, prejudicada pela ausência de experiência e tempo hábil para aprender, nos quais, necessitam repensar estratégias e a práxis docente, sobretudo, a posição deste no ERE, atuando como mediador do saber (Aguiar, Paniago \& Cunha, 2020). Contudo, o cenário complexo causado pela pandemia, também provocou os professores a mudarem suas práticas de ensino, buscando, por exemplo, utilizar a pesquisa como alternativa de aprendizagem docente.

Diante deste contexto, fica evidente na vivência dos eventos da pandemia que a educação não será mais a mesma, forçando novos meios de "se fazer educação". Fatos que levantam incógnitas acerca de sua amplitude de eficácia e consequência perante professores e alunos, por isso a necessidade de análise quanto à adequação da nova educação. 


\section{Metodologia}

A metodologia utilizada neste estudo foi a quanti-qualitativa, uma vez que quantifica e analisa os dados obtidos através do questionário online (Google Forms) a partir de ferramentas estatísticas, além de interpretá-los em vista da realidade na qual os alunos estão inseridos (Souza et al. 2017; Schneider et al. 2017). Entendemos por abordagem qualitativa a captação e análise de dados por meio de uma perspectiva indutiva, no qual, valoriza a inferência e não a frequência das informações estudadas, em um contexto não-generalizado (Lüdke \& André, 2013; Bardin, 2016). Os elementos descritivos provêm de um longo período de imersão em instituições escolares, por exemplo, sob narrativas observadoras ou participativas, dispostos em diferentes materiais escritos e audiovisuais, onde se preza toda a significação argumentativa dos participantes, por meio das variáveis de inferência específicas, ao possibilitar a formulação de hipóteses, ancoradas em um pretexto teórico (Lüdke \& André,2013; Bardin, 2016).

Ao objetivar identificar as possibilidades e desafios na aprendizagem de estudantes do ensino médio no ERE, utilizamos como instrumento de coleta de dados, um questionário aplicado via (Google Forms) com 9 turmas do Ensino Médio $\left(1^{\circ}, 2^{\circ}\right.$ e $3^{\circ}$ anos). No total 77 alunos responderam. O questionário foi organizado em três seções: Informações pessoais (questões 1 e 2); meios utilizados para o acesso às atividades remotas (questões 3 e 4); e a Adaptação, pontos positivos e negativos da aprendizagem por meio das atividades remotas (questões 5,6 e 7). Na primeira seção perguntou-se o nome e a série do estudante. Na segunda, qual o equipamento utilizado para acessar as atividades remotas e em qual plataforma. Na terceira e última parte do questionário, se o aluno se adaptou ou não ao ERE, e quais são, para ele, os pontos positivos e negativos desta metodologia utilizada pelo colégio. Os dados foram todos plotados em gráficos (com exceção da questão 1).

Para a análise dos dados, utilizou-se plataforma Microsoft Excel 2016, tendo como base o método de Análise Classificativa, no qual, o conjunto de informações fora investigado de forma individual, com base nas relações psicológicas estabelecidas em relação à modalidade de ensino não presencial e sua vivência neste período, cujos tópicos eram subdivididos em unidades de registro, por exemplo: continuidade dos estudos, acompanhamento de pais e avós na execução de atividades. A codificação foi efetuada a partir das inferências gerais e específicas, ou seja, pela inter-relação entre asserções lógicas adotadas e preestabelecidas na análise, o que corrobora para determinar a causa e o efeito de determinada afirmação, resultante na detecção de problemáticas e fragilidades no ensino público básico, nesse contexto (Bardin, 2016).

\section{A Aprendizagem na Pandemia nas Vozes de Alunos do Ensino Médio: o que Revelam os Dados?}

Para entender a percepção dos alunos em relação ao ERE, nós analisamos as respostas do questionário, identificando temas que são comuns entre os estudantes, organizando um processo de categorização com os dados, considerando o objetivo da pesquisa que foi identificar as possibilidades e desafios na aprendizagem dos estudantes.

Assim, a primeira seção do questionário foi composta por duas questões, sendo a primeira relacionada ao nome dos participantes. Com as respostas pudemos constatar que 67\% (52 de 77) dos participantes são do sexo feminino e $33 \%$ ( 25 de 77 ) são do sexo masculino.

Dos respondentes, cerca de 70\% (56 de 77 dos participantes) estavam nos dois anos finais do ensino médio (Figura 1). Por certo, estudar nos anos finais do ensino médio representa uma certa pressão em sair bem nos estudos, devido ao ENEM - Exame Nacional do Ensino Médio, institucionalizado pela Portaria no 438, de 28/05/1998, cujo objetivo é de avaliar as habilidades dos discentes egressos (Brasil, 1998). Assim, este exame, que é a porta de entrada para o ingresso em uma instituição de ensino superior, provoca nos estudantes, abalos emocionais e os instiga a intensificar ainda mais os estudos no período da pandemia (Malta et al., 2020). 
Figura 1. Quantitativo de estudantes em relação às séries que estão cursando.

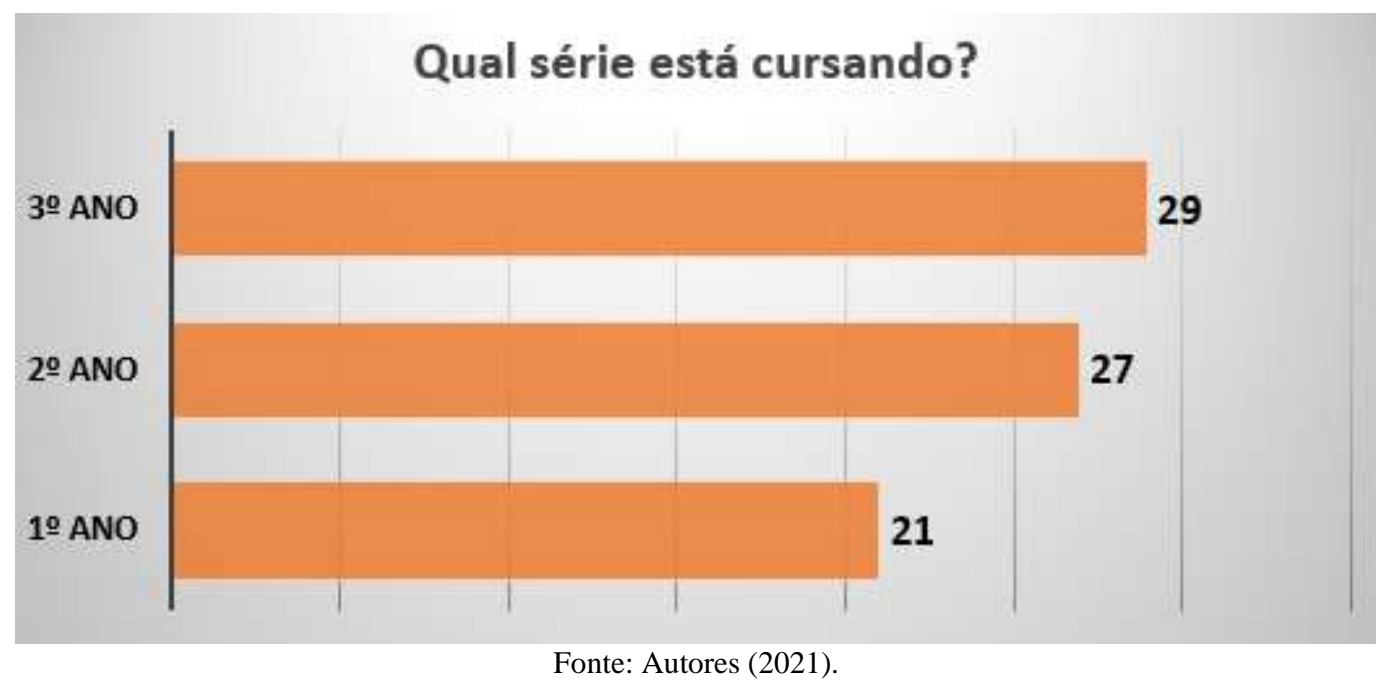

Diante da necessidade de continuidade dos estudos, o ERE foi uma alternativa adotada na maior parte das escolas; porém, existem problemas relacionados a tal estratégia de ensino-aprendizagem, como a falta de equipamentos e/ou dificuldade na adaptação nas aulas remotas. Com a segunda seção do questionário podemos observar que cerca de $85 \%$ dos participantes utilizam celular e/ou notebook para assistir às aulas e realizar as atividades propostas pelos professores. O que neste caso, não condiz com a realidade majoritária no país, uma vez que o Brasil tem um dos maiores índices de desigualdade do mundo, chegando ao nono lugar em 2020 segundo o IBGE (O GLOBO, 2020), neste contexto, a desigualdade social marca com caráter concreto, estrutural e histórico a sociedade como um todo, dificultando ainda mais a acessibilidade estudantil de muitos alunos (Conceicao, 2021), de longe, o acesso à educação é um dos fatores que mais contribuem para o aumento da inequidade e permanência escolar (Penteado \& Guzzo, 2010), ainda maior em tempos de pandemia, fator o qual ainda traz maiores questionamentos, quanto sua aceitabilidade, adequação e taxa de eficácia. Por exemplo, quando analisamos as respostas dos participantes na figura 2 (Adaptação), percebemos que cerca de 64\% (49 de 77) dos participantes responderam que não estão se adaptando às aulas remotas, ou que estão, mas com dificuldades (Figura 2). Esses dados se mostram preocupantes, visto que quase $50 \%$ dos que responderam essas opções estão no segundo ou terceiro ano do ensino médio. Ou seja, os estudantes que estão prestes a realizar o ENEM não se adaptaram ao ERE, o que representa um déficit na aprendizagem desses estudantes; assim como o aumento na desigualdade de oportunidades para conseguir ingressar no ensino superior. Médici et al. (2020) observaram que a maioria dos estudantes de escolas privadas relatam que o ERE não está contribuindo para uma formação adequada na qual possam estar aptos a realizar o ENEM; o estudo evidencia também que esta situação é ainda mais agravante quando comparado com os estudantes de escolas públicas. 
Figura 2. Respostas dos estudantes em relação a adaptação às aulas remotas. Nota-se que a maioria estão se adaptando, porém com dificuldades.

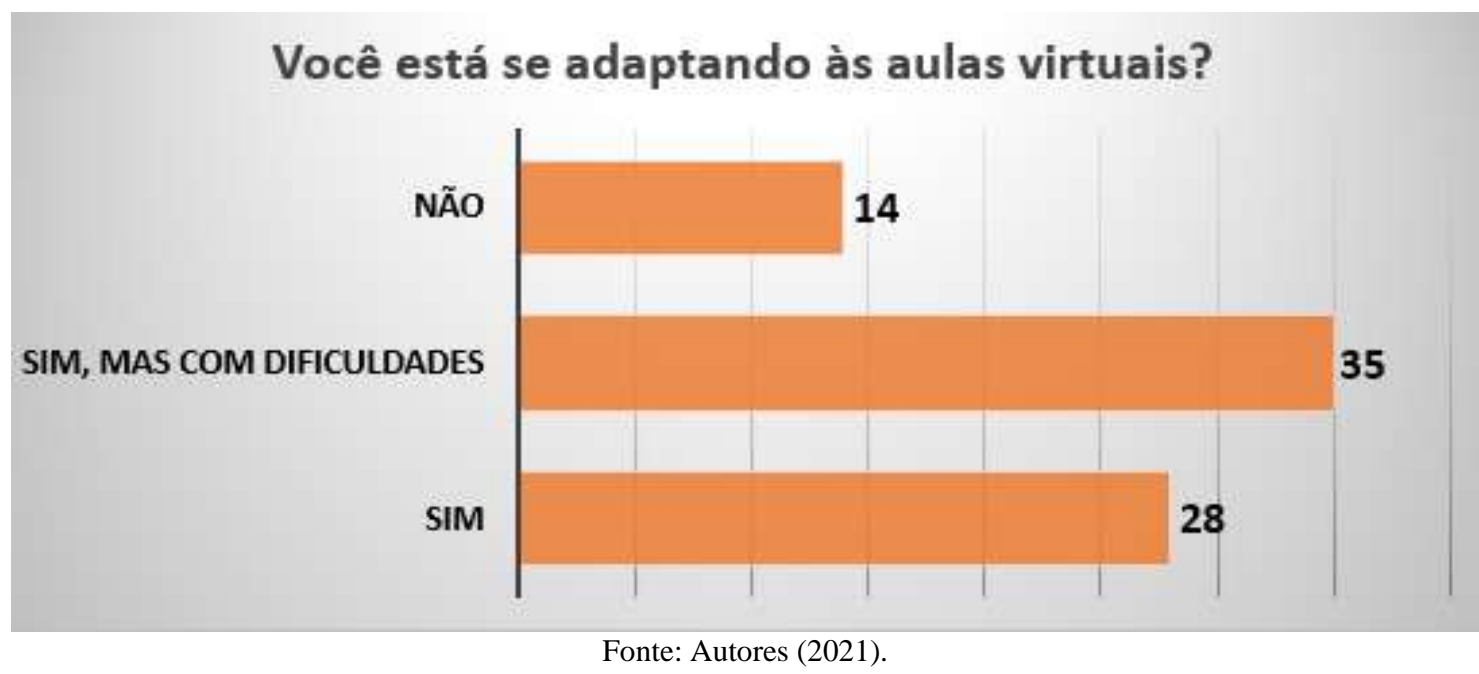

Ainda na terceira seção do questionário, nós perguntamos quais os desafios e positivos, possibilidades em relação às aulas virtuais, sendo organizados os dados em três subcategorias. Para as possibilidades, sinalizamos: 1) Continuidade dos estudos; 2) possibilidade de estudar em casa; 3) Flexibilização de horário (Figura 3). E para os desafios destacamos: 1) Diminuição no aprendizado; 2) Ausência de contato físico; Dificuldades de concentração e atenção" (Figura 4).

Figura 3. Principais temas de respostas dos alunos quando perguntado os principais pontos positivos das aulas virtuais. O quantitativo de 17 estudantes que entenderam como ponto positivo os estudos em casa, representam $22 \%$ do total que responderam o questionário.

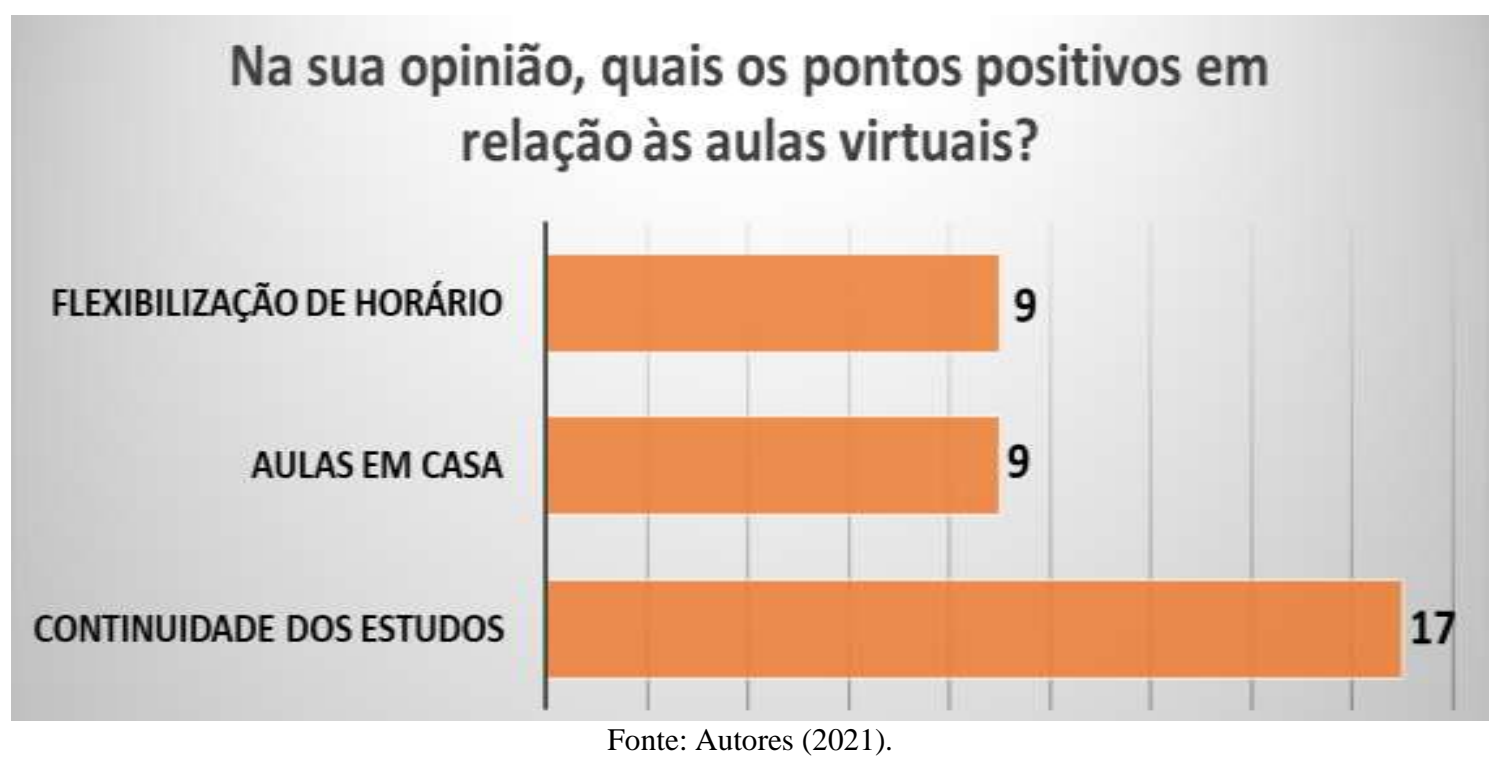

\subsection{As possibilidades do ensino remoto na aprendizagem dos alunos}

A continuidade dos estudos, foi uma das possibilidades sinalizadas pelos alunos. Na situação adversa que enfrentamos fez-se necessário o uso de tecnologias, para que assim fosse garantido o direito de todos à educação (Brasil, 2020), ainda que, a partir da Portaria $\mathrm{n}^{\circ} 343$, o MEC tenha decretado a suspensão das aulas presenciais em território nacional , assim como o estado de Goiás, por meio das Resoluções no 2, de 17/03/2020, nº 5, de 01/04/2020, e n ${ }^{\circ} 15$, de 10/08/2020, nas quais estabeleceram o 
Regime Especial de Aulas Não-Presenciais, a fim de evitar o contágio pelo Covid-19, no período de 17/03/2020-19/12/2020, em face ao agravamento do quadro pandêmico (Goiás, 2020 a,b,c).

Nesse processo de adequar o ensino à situação atual percebeu-se a dificuldade dos professores em articular o uso destas tecnologias no processo de ensino-aprendizagem (Rocha et al. 2020). Além da dificuldade encontrada pelo corpo docente, o corpo discente, os educandos, fazem parte desse processo educativo, visto que a educação ocorre no diálogo (Freire, 1974). Por isso, qualquer mudança realizada no ensino deve atentar-se aos alunos e às suas realidades, para que de algum modo as mudanças realizadas gerem menos impactos negativos (Pedrosa, 2020).

Ainda assim, foi levantado a opinião dos alunos em relação à continuidade dos estudos pelo modo remoto e o resultado foi considerável, cerca de 22\% (17 de 77) comentaram que a continuidade dos estudos foi um ponto positivo. Nesse sentido, mesmo que o ERE que apresente fragilidades, e seja temporário, possibilitou a sequencialidade do ensino assegurando, de algum modo, a formação dos alunos para provas que estes farão, como por exemplo ENEM e vestibulares. Além de proporcionar um ambiente pedagógico diferente do tradicional, no qual o aluno tem de tornar-se ativo no processo de ensino-aprendizagem (Nascimento, 2020).

Outra possibilidade foi a possibilidade de estudar em casa. Todas as instituições de ensino tiveram uma paralisação total de suas aulas presenciais, adolescentes, crianças e adultos, seja do ensino básico ao superior tiveram que se adaptar rapidamente a aulas remotas e consequentemente dar continuidade aos estudos em casa (Moreira et al., 2020). Cerca de $12 \%$ dos alunos entrevistados ( 9 de 77) entendem que os estudos em casa foram um dos pontos positivos do ensino durante a pandemia. Entretanto podemos observar certa ambiguidade ao considerar os estudos em casa como um ponto positivo, no Brasil hoje 4,8 milhões de crianças e adolescentes, entre 9 e 17 anos, não possuem acesso à internet em casa e $58 \%$ dos jovens possuem acesso à internet, porém não possuem computador de mesa ou notebook realizando os estudos assim através de smartphones, dificultando mais ainda o processo de ensino-aprendizagem (Stevanim, 2020).

Um dos obstáculos de importante relevância é a exclusão digital, tanto para docentes e discentes, mesmo com pacotes de internet oferecidos e dispositivos compatíveis, grande parte dos estudantes não conseguem acompanhar as aulas remotas por não dispor de uma local adequado para os estudos e por muita das vezes ter que dividir os aparelhos eletrônicos com família (Moreira et al., 2020). Um local de estudo silencioso é fundamental para concentração e dentro de casa muitas das vezes os estudantes não conseguem ter um local apropriado e além das diversas distrações como TV, videogames, smartphones e tablets.

Outro aspecto que vem fragilizando os estudos em casa são os problemas relacionados à saúde mental e física dos discentes. Uma mudança brusca no estilo de vida causada pela pandemia como a restrição social acarretando na redução de atividades físicas e no aumento do comportamento sedentário, uma grande alteração de hábitos alimentares (Malta et al., 2020). A dimensão do impacto ocasionado pela COVID-19 na vida dos estudantes é de alta grandeza, como consequência depressão, ansiedade, crises de pânico e grande insegurança prejudicando totalmente o progresso dos estudantes e fragilizando as aulas remotas (Maia, 2020).

Entretanto, em contrapartida o ensino em casa nos traz algumas vantagens, tais como liberdade maior no horário destinado aos estudos, um ensino mais ativo por parte do aluno e diversos aprendizados relacionados ao uso tecnologias educacionais, que por conta da transição tiveram que aprender e utilizar sistemas de videoconferência, como Google Meet, Skype, Google Classroom, Zoom, plataforma Moodle, Microsoft Teams e Google Hangouts (Moreira et al, 2020). O ensino em casa no Brasil já realidade de diversas famílias, não só no Brasil como em diversos países o HOMESCHOOLING vem crescendo de forma exponencial e com a chegada da pandemia causada pelo Covid-19 obviamente adotaram os estudos em casa (Barbosa, 2011).

Como isso, fica evidente as mudanças e impactos causados na vida dos estudantes, segundo Moran (2000), com a versatilidade no ensino sempre devemos seguir o caminho da adaptação buscando o respeito em diversos ritmos de 
aprendizagem, as diferenças individuais, fazendo com que as diferenças locais se integrem com os contextos culturais, existe uma grande gama de informações e diversas dificuldades em escolher quais são as mais significativas no processo de ensinoaprendizagem.

E por fim, os alunos destacaram a flexibilização de horário, como aspecto importante na sua aprendizagem.

Diante da crise que enfrentamos, impossibilitando o ensino presencial, a continuidade de ensino-aprendizagem remoto, como mencionado, é necessária, porém, esta mudança do processo educativo levanta outra questão: a educação ocorre na relação professor-aluno e destes com o mundo, mas não no vazio, há a necessidade de um ambiente no qual tenha estas relações (Freire, 1996).

Temos somente o ambiente virtual para promover a educação. Deste modo, a compreensão deste meio virtual nos dará parâmetros para o ensino-aprendizagem. Considerando também que os alunos destacaram que o ambiente interfere no processo educativo. Percebe-se que não tendo a limitação de um espaço presencial, há por consequência a flexibilização tanto de conteúdo, quanto de horários (Godoi et al. 2020). Neste ambiente o modelo tradicional de ensino sofre uma ruptura e abre-se então uma grande oportunidade de se utilizar as metodologias ativas (Dosea et al. 2020).

Como a maneira de ensinar e aprender é agora mediada pelas tecnologias, que promovem maior flexibilidade, se requer mais compromisso do educando, uma vez que não há a exigência diária de se preparar e ir à escola por algumas horas. $\mathrm{O}$ aluno possui a liberdade de se organizar e planejar ao longo do dia, e da semana, períodos de estudo. Esta dinâmica, que por um lado favorece a autonomia dos discentes, por outro, leva à diminuição do desempenho destes, pois revela a ausência daquela (Lima, 2020).

Portanto, nesta situação ambígua entende-se o porquê de a flexibilidade de horários para a realização das atividades escolares ter cerca de 12\% (9 de 77) dos estudantes entendendo-a como um dos pontos positivos do REANP. O problema é a liberdade. $\mathrm{O}$ aluno deve aprender a lidar com a possibilidade de não se restringir a um ambiente físico escolar, e a responsabilidade de desenvolver o hábito de autoaprendizagem (Godoi et al. 2020).

Figura 4. Principais temas destacados nas respostas dos alunos em relação às aulas virtuais. Cerca de $30 \%$ dos alunos que responderam o questionário relataram que o baixo aprendizado é um ponto negativo do ERE.

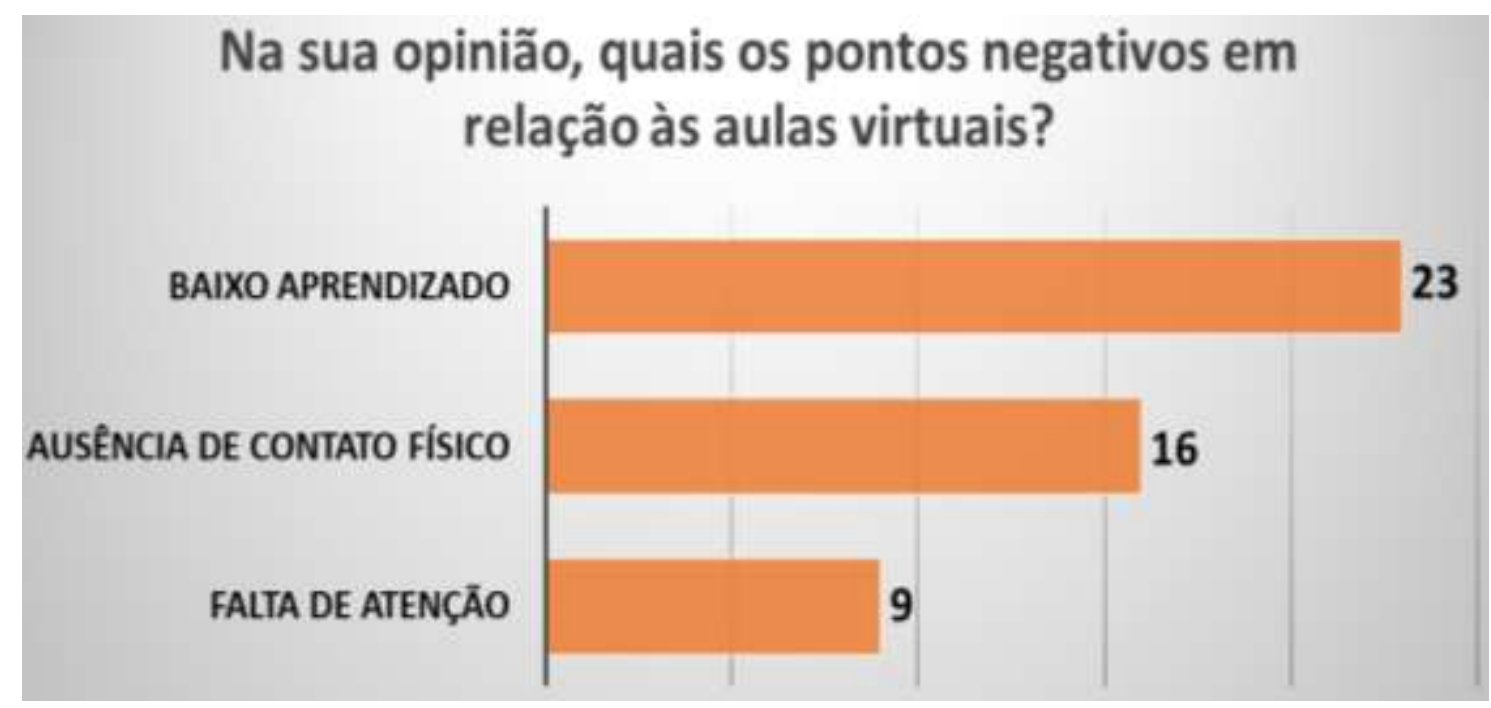

Fonte: Autores (2021). 


\subsection{Os efeitos perversos da pandemia na aprendizagem dos alunos do Ensino Médio}

A pandemia do novo Coronavírus aumentou ainda mais a crise que já existia na educação brasileira, e a baixa aprendizagem está entre os pontos que caracterizam essa crise (Silva, 2020). Neste contexto, cerca de 30\% (23 dos 77) dos estudantes disseram que o baixo aprendizado é um dos pontos negativos do REANP, sendo um quantitativo alarmante considerando que os alunos estão se preparando para o ENEM.

O professor em sala de aula almeja o desenvolvimento do aluno; assim como destacado por Filho (2020), o professor busca desenvolver a autoestima de seus alunos dentro de um ambiente tranquilo, que estimule suas capacidades de perdoar e de socializar. Considerando que o professor pode identificar quando o processo de construção do conhecimento está eficiente (Maldonado, 1994), como ele pode reconhecer esse processo estando em aulas remotas? Podemos não saber a resposta exata, no entanto, existem maneiras de remediar a baixa aprendizagem que os estudantes alegam com o ERE. Demo e Silva (2020), relatam que o protagonismo estudantil pode ser uma chance de reinventar a escola; considerando que o protagonismo dos alunos não só valoriza a função mediadora dos professores, mas também se tornam parceiros para com a aprendizagem, esta concepção parece ser uma importante escolha no ensino remoto.

Analisando as respostas das professoras em um questionário, Aguiar e Goulart (2020) perceberam que a aprendizagem dos estudantes estava relacionada com a afetividade, e que problemas emocionais podem ser agentes responsáveis pela baixa aprendizagem. As autoras relataram que parcerias para solucionar esses problemas mais complexos são essenciais, como comentado pelas professoras participantes da pesquisa, a família e a gestão escolar precisam ser protagonistas em tais resoluções. Constatamos que a afetividade, ou mesmo ausência de contato, foi um dos pontos negativos mais reportados pelos alunos, o que nos leva a entender que muitos problemas no ensino presencial foram transferidos e podem até ter sido piorados com o ensino remoto.

Outro desafio apontado, foi a ausência de contato. Ao transferir as aulas para o modo virtual surgiram-se várias discussões ao que concerne a importância do contato entre os alunos para uma melhora no processo de ensino-aprendizagem. Costa e Silva (2020) comentaram que a necessidade de distanciamento social lembrou que o contato olho no olho, ou mesmo atos corriqueiros, são causas constituintes da condição humana. E esta perspectiva foi uma das mais evidenciadas, em nosso estudo, pelos alunos como ponto negativo das aulas remotas, representando cerca de 20\% (16 dos 77 estudantes) dos pontos negativos. Além disso, um estudo da Casado (2020) mostrou que os professores relatam o mesmo problema que os alunos, sendo que o não contato entre alunos e professores é uma das causas que representa a insuficiência do modelo de ensino remoto.

Um aspecto que se torna ainda mais fragilizado com o ERE é o da educação de alunos com deficiência. Neta et al. (2020) apontou vulnerabilidade no atendimento aos estudantes com necessidades especiais, o que representa prejuízos irrecuperáveis, caracterizando a exclusão destes alunos dos processos de ensino-aprendizagem. Este problema se torna ainda maior com a pandemia, onde a ausência de contato do aluno com o ambiente escolar dificulta o acesso às informações. As autoras ainda relatam que a ausência e/ou disponibilização de recursos tecnológicos acentuam tal problemática, já que isto leva a falta de acesso a plataformas educativas e internet.

É evidente que a utilização das TDICs ajudou na continuidade dos estudos de modo remoto; no entanto, será de grande importância o surgimento de uma nova relação entre professores e alunos comecem no ambiente escolar, entendendo que o professor tem um papel social (LOPES, 2017). Autores também relatam que o ensino a distância apresenta um problema característico em comparação com o ambiente presencial no que se concerne a comunicação interação sociais (MARCONDES et al. 2014), eles ressaltaram que no ambiente presencial o professor consegue identificar, pelo contato visual, a compreensão do aluno pelas expressões corporais, conseguindo identificar se os alunos compreenderam o tema explicado.

Neste contexto, compreendemos que o contato entre professores e alunos e entre alunos e ambiente escolar representa uma importante etapa na construção do conhecimento. No primeiro caso, o contato entre professores e alunos está relacionado 
com a afetividade que, por sua vez, está relacionado com o aprendizado dos estudantes; no segundo caso, o aluno em contato com o ambiente escolar propicia a difusão das informações favorecendo um ambiente participativo, assim como para a inclusão de todos os alunos: que tenham deficiência e/ou são de classes sociais menos favorecidas.

Também verificamos que a falta de atenção é um elemento desafiante do ensino remoto.

O início das aulas remotas aumentou a dispersão da atenção dos alunos, como apontado por 12\% (9 de 77) dos estudantes como pontos negativos do REANP. Houve uma grande necessidade de os alunos direcionaram sua atenção para jogos e conversas virtuais escolares, mudando assim, a concentração para sua aprendizagem como enfatizado no estudo de Catanante et al. (2020). Foi concluído no estudo citado que muitas variáveis intervêm para com o processo de ensino-aprendizagem, principalmente a ausência ou deficiência de suporte técnico e profissional como evidenciamos anteriormente. O principal problema que pode impactar diretamente na falta de atenção do aluno em casa é justamente estar em um ambiente familiar, onde as pessoas deste ambiente causam a perda de foco do aluno às atividades; por vezes querer que o estudante interaja com seus familiares, ou mesmo por conflitos entre os familiares.

Diversas alternativas vêm sendo propostas para amenizar a situação, como quizzes, objetos inanimados, etc. Leffa et al. (2017) comenta que os quizzes facilitam o aprendizado dos alunos e ainda pode ser um fator que torne o assunto mais didático, conquistando a atenção dos alunos para com o conteúdo ministrado pelos professores. Um estudo sobre aventuras e desventuras no ensino remoto, uma professora de história comenta que utiliza bonecos para explicar os conteúdos, afirma que tal prática pode chamar a atenção dos estudantes durante a aula; nas aulas, a professora parte de narrativas históricas, decisivas em contextos de sociedades, para conseguir aplicar tal metodologia de ensino (Costa, 2020). A gamificação também têm se tornado grande opção para o desenvolvimento criativo das aulas, essa abordagem é semelhante ao quiz; no entanto, a gamificação considera a utilização design de games em concepções fora dos jogos, como maneira de reter a atenção dos estudantes (Oliveira, 2021).

Ao abordarmos a falta de atenção dos alunos no ensino remoto vemos que os professores apresentam diferentes abordagens em suas aulas, sempre com o intuito de manter a atenção do aluno para com o conteúdo que está sendo ministrado. Nesta perspectiva, os professores tiveram que se reinventar para manter as aulas em um nível que os estudantes possam aprender e, sem o auxílio das entidades governamentais, melhorar seu acesso as TDICs, ou mesmo comprar suporte técnico para suas aulas como computador e rede de internet. Ainda assim, os docentes procuram condições para o melhor rendimento dos alunos e consequentemente o aproveitamento escolar para a realização de provas como ENEM e vestibulares. Schimiguel et al. (2020) relatam a importância de organizar a distribuição do tempo, como sugestão a divisão entre explicações do conteúdo, discussão e interação aluno-professor e aluno-aluno, mantendo a energia e aumentando o dinamismo da aula; comentam que essas ações podem atrair a atenção dos estudantes, com informações claras e motivando o aprendizado entre os alunos.

Os problemas enfrentados pelos alunos acabam gerando uma aversão ao ERE, desconsiderada como um método eficiente para o ensino, diferentemente das aulas presenciais; no entanto, muitos alunos destacam diversos pontos positivos acerca do ensino, tendo como base a flexibilização de horários, prosseguimento dos estudos, localização confortável, havendo a liberdade de estudar tópicos de maior relevância (Médici et al. 2020; Alves et al. 2020). É de suma importância que a instituição de ensino esteja disposta a escutar o aluno e entender suas necessidades e dificuldades.

\section{Considerações Finais}

Ao objetivar identificar as possibilidades e desafios na aprendizagem de estudantes do ensino médio no ERE, constatamos que o ensino remoto operado no contexto da pandemia da Covid-19, impactou de forma crucial na vida e na aprendizagem dos jovens estudantes do ensino médio, provocando possibilidades e também efeitos perversos.

Do ponto de vista da possiblidade, vemos que o Ensino Remoto possibilitou uma reorganização no modo de estudos, em que os estudantes adquiriram autonomia e liberdade para estudar em um ambiente confortável, nos horários desejados, de 
modo que a aprendizagem é constantemente ativa e significativa para os sujeitos envolvidos no processo, ao incitar novas formas e metodologias para a compreensão do conteúdo.

Apesar das possibilidades, não podemos silenciar os efeitos perversos provenientes da adaptação imediata ao ERE, no qual, denota-se o baixo aprendizado, influenciado por uma série de fatores externos, tal como a ausência de comunicação entre professores e alunos, ausência de contato direto, de grande relevância para o processo de ensino-aprendizagem e, sobretudo, a falta de atenção, corroborada pelo ambiente familiar, fomentando um comodismo, poluição sonora, constantes interrupções, além de cansaço para estudar. Para tanto, o sistema de ensino remoto revelou uma problemática crônica no ensino público brasileiro, cujo acesso às aulas é limitado pela falta de aparelhos adequados, internet de qualidade e tempo dedicado ao estudo, ao estratificar a formação sócio-critica e igualitária de todos os alunos.

Em suma, esta pesquisa sinalizou o quão é importante compreender as opiniões de alunos do ensino médio acerca da continuidade das aulas pelo modo remoto, o comumente denominado ERE. A ideia primordial é mostrar que a visão dos estudantes, em relação a este modelo de ensino, representa uma importante etapa do diagnóstico escolar; e pode contribuir para com futuros projetos de intervenção nas escolas. As intervenções são necessárias, uma vez que este modelo foi recém aplicado, e consideramos que futuras readequações são necessárias para a melhora no processo de ensino-aprendizagem. Desta forma, este estudo contribui evidenciando que os alunos também representam importantes fontes de informações para discussões de continuidade e aprimoramento das metodologias de ensino de modo remoto.

Subsecutivamente no presente trabalho evidenciam-se fatores favoráveis que indicam grande usufruo pedagógico. Podendo ainda ressaltar aspectos que indubitavelmente servirão como recurso de futuros trabalhos tais como: salientar quais recursos tecnológicos podem auxiliar tanto à distância quanto presencialmente que permitam melhor aproveitamento conceitual; estudar fatores de impacto na acessibilidade e inclusão equalitária entre alunos e professores; propor metodologias e ferramentas específicas que busquem maior interatividade entre professor-aluno; caminhos efetivos que transfigurem os efeitos perversos consequentes do $\mathrm{EaD}$; estudo alargado envolvendo mais grupos e diferentes realidades.

\section{Agradecimentos}

Agradecemos ao Instituto Federal Goiano - Campus Rio Verde e à docente R. N. P., pela disponibilidade e colaboração para a realização deste trabalho.

\section{Referências}

Aguiar, J. V. \& Goulart, M. (2020). Relação afetiva professor-criança no ensino fundamental I em escolas estaduais do município de Tubarão/SC. PedagogiaTubarão, UNISUL. http://www.riuni.unisul.br/handle/12345/10244.

Aguiar, L., Paniago, R. N. \& Cunha, F. S. R. (2020). Os impactos do coronavírus no saber fazer docente dos professores do ensino médio integral. Itinerarius Reflexionis - Dossiê: Educação Brasileira e a Ead no contexto da pandemia de Covid- 19: perspectivas e desafios, 16 (1), 1-22, Jataí. https://doi.org/10.5216/rir.v16i1.65352

O Globo (2020). "Brasil é o nono país mais desigual do mundo, diz IBGE." Exame. https://exame.com/economia/brasil-e-nono-pais-mais-desigual-do-mundodiz-ibge/

Alves, E. J., Castro, F. J., Vizolli, I., Neto, M. S. A. \& Nunes, S. G. C. (2020). Impactos da pandemia covid 19 na vida acadêmica dos estudantes do ensino a distância na Universidade Federal do Tocantins. Aturá-Revista Pan-Amazônica de Comunicação, 4 (2), 19-37. https://doi.org/10.20873/uft.2526$8031.2020 \mathrm{v} 4 \mathrm{n} 2 \mathrm{p} 19$

Barbosa, L. M. R. (2011). Ensino em casa no Brasil: reflexões a partir da experiência canadense. Simpósio Brasileiro, 24. Congresso Ibero-americano de Política e Administração da Educação/Jubileu de Ouro da Anpae, Anais [...],11, 1-5, PUC-SP, https://www.anpae.org.br/simposio2011/cdrom201 1/PDFs/trabalhosCompletos/posters/0089.pdf

Bardin, L. Análise de Conteúdo. (2016). 65-168, Editora 70.

Brasil. Ministério da Educação. (1998). Portaria $\mathrm{n}^{\circ}$ 438, de 28 de Maio de 1998. Diário Oficial da União, no 102-E, Seção 1, p. 5. http://www.editoramagister.com/doc_348638_PORTARIA_N_438_DE_28_DE_MAIO_DE_1998.aspx. 
Brasil. Ministério da Educação. (2020). Base Nacional Comum Curricular. Brasília. http://basenacionalcomum.mec.gov.br/.

Catanante, F., Campos, R. C. \& Loiola, I. (2020). Aulas on-line durante a pandemia: condições de acesso asseguram a participação do aluno? Revista Educ@ ção Científica, 4, (8), 977-988.

Conceição, V. L. \& Zamora, M. H. R. N. (2015). Desigualdade social na escola. Estudos de Psicologia (Campinas), 32 (4), $705-714$. https://doi.org/10.1590/0103-166X2015000400013

Costa, J. S. \& Silva, E. F. (2020). As influências da relação pedagógica professor-aluno no processo de ensino-aprendizagem: o diálogo como fundamental para o ato educativo. VII Congresso Nacional de Educação, Maceió. https://editorarealize.com.br/editora/anais/conedu/2020/TRABAL HO_EV140_MD1_SA2_ID6972_24092020190428.pdf

Demo, P. \& Silva, R. A. (2020). Protagonismo estudantil. Organizações e Democracia, 21 (1), 71-92. https://doi.org/10.36311/1519-0110.2020.v21n1.p71-92.

Dosea, G. S., Rosário, R. W. S., Silva, E. A.; Firmino, L. R. \& Oliveira, A. M. S. (2020). Métodos ativos de aprendizagem no ensino online: a opinião de universitários durante a pandemia de COVID-19. Interfaces Científicas-Educação, 10 (1), 137-148. https://doi.org/10.17564/2316-3828.2020v10n1p137-148.

Filho, A. L. O. P. (2020). Afetividade e acolhimento como ferramentas na consolidação da aprendizagem: Um caso em uma faculdade particular na cidade de Natal/RN, Educação: Agregando, Incluindo e Almejando Oportunidades 5, 16-30, Atena Editora, Ponta Grossa, Paraná. 10.22533/at.ed.1602021093

Freire, P. (1974). Pedagogia do Oprimido. Paz e Terra.

Freire, P. (1996). Pedagogia da Autonomia: saberes necessários à prática educativa, Paz e Terra.

Godoi, M., Kawashima, L. B., Gomes, L. A. \& Caneva, C. (2020). O ensino remoto durante a pandemia de covid-19: desafios, aprendizagens e expectativas dos professores universitários de Educação Física, Research, Society and Development, 9 (10), 1-19. https://doi.org/10.33448/rsd-v9i10.8734.

Goiás. CEE. (2020a). Resolução CEE/CP No2/2020, de 17 de março de 2020. https://cee.go.gov.br/resolucao-022020-sobre-o-regime-especial-de-aulas-naopresenciais/

Goiás. CEE. (2020b). Resolução CEE/CP N ${ }^{\circ}$ 05, de 01 de abril de 2020. https://cee.go.gov.br/wp-content/uploads/2020/04/Resoluc\%CC\%A7a\%CC\%83o-CEECP-N.-05-2020.pdf.pdf

Goiás. CEE. (2020c). Resolução CEE/CP N. 15, de 10 de agosto de 2020. https://site.educacao.go.gov.br/wp-content/uploads/2020/08/Resolu\%C3\%A7\%C 3\%A3o- CE E-CP-15_2020_-REANP-19_12.pdf

Leffa, V. J., Costa, A. R., Beviláqua, A. F. \& Fialho, V. R. (2017). Preferência dos estudantes na aprendizagem de línguas em três atividades do Moodle. Revista Brasileira de Linguística Aplicada, 17 (1), 113-136, Belo Horizonte. https://doi.org/10.1590/1984-6398201610232.

Lima, F. B. (2020). Ensino remoto em tempos de Covid-19: percepções de alunos do curso de Letras. Palimpsesto-Revista do Programa de Pós-Graduação em Letras da UERJ, 19 (34), 60-78. https://doi.org/10.12957/palimpsesto.2020.54136

Lopes, R. C. S. (2017). A relação professor aluno e o processo ensino aprendizagem. Dia a dia $e$ educação, 9, 1-28. http://www.diaadiaeducacao.pr.gov.br/portals/pde/arquivos/1534-8.pdf

Lüdke, M. \& André, M. E. D. A. (2013). Abordagens qualitativas de pesquisa: a pesquisa etnográfica e estudo de caso. In: Pesquisa em Educação: Abordagens Qualitativas, $2^{\mathrm{a}}$ ed., 12-28, Grupo GEN, Editora E.P.U.

Maia, B. R. \& Dias, P. C. (2020). Ansiedade, depressão e estresse em estudantes universitários: o impacto da COVID-19. Estudos de Psicologia, 37 (1), 1-8, Campinas. https://doi.org/10.1590/1982-0275202037e200067.

Maldonado, M. T. (1994). Aprendizagem e afetividade. Revista de Educação AEC, 23 (91), 37-44. http://www.inicepg.univap.b r/cd/INIC_2007/trabalhos/humanas/inic/INICG00785_01O.pdf

Malta, D. C., Szwarcwald, C., Barros, M. B. A., Gomes, C. S., Machado, Í. E., Júnior, P. R. B. S., Romero, D. E., Lima, M. G., Damacena, G. N., Pina, M. F., Freitas, M. I. F., Werneck, A. O., Silva, D. R. P., Azevedo, L. O. \& Gracie, R. (2020). A pandemia da COVID-19 e as mudanças no estilo de vida dos brasileiros adultos: um estudo transversal. Epidemiologia e Serviços de Saúde, 29, 1-13. https://doi.org/10.1590/S1679-49742020000400026

Marcondes, L. N. L. \& Degásperi, A. (2014). A afetividade como instrumento no EaD. Revista Paidéi@-Revista Científica de Educação a Distância, 6 (10). https://periodicos.unimesvirtual.com.br/index.php/paideia/article/view/373/375

Médici, M. S., Tatto, E. R. \& Leão, M. F. (2020). Percepções de estudantes do Ensino Médio das redes pública e privada sobre atividades remotas ofertadas em tempos de pandemia do coronavírus. Revista Thema, 18, 136-155. 10.15536/thema.V18.Especial.2020.136-155.1837

Moran, J. M. (2000). Ensino e aprendizagem inovadores com tecnologias. Informática na educação: teoria \& prática, 3 (1), 137-144. https://doi.org/10.22456/1982-1654.6474.

Moreira, J. A., Henriques, S. \& Barros, D. M. V. (2020). Transitando de um ensino remoto emergencial para uma educação digital em rede, em tempos de pandemia. Dialogia, (34), 351-364, São Paulo. 10.5585/Dialogia.N34.17123

Nascimento, F. G. M. \& Rosa, J. V. A. (2020). Princípio da sala de aula invertida: uma ferramenta para o ensino de química em tempos de pandemia. Brazilian Journal of Development, 6 (6), 38513-38525.

Neta, A. S. O., Nascimento, R. M. \& Falcão, G. M. B. (2020). A Educação dos Estudantes com Deficiência em Tempos de Pandemia de Covid-19. Interaç̧ões, 16 (54), 25-48. https://doi.org/10.25755/int.21070 
Research, Society and Development, v. 10, n. 8, e32210817436, 2021

(CC BY 4.0) | ISSN 2525-3409 | DOI: http://dx.doi.org/10.33448/rsd-v10i8.17436

Oliveira, M. B., Silva, L. C. T., Canazaro, J. V., Carvalhido, M. L. L., Souza, R. R. C. D., Neto, J. B., Rangel, D. P. \& Pelegrini, J. F. M. (2021). O ensino híbrido no Brasil após pandemia do covid-19. Brazilian Journal of Development, 7 (1), 918-932. https://doi.org/10.34117/bjdv7n1-061

Pedrosa, G. F. S. (2020). O uso de tecnologias na prática docente em um pré-vestibular durante a pandemia da covid-19. Boletim de Conjuntura (BOCA), ano II, 2 (6), 86-91, Boa Vista. http://dx.doi.org/10.5281/zenodo.3843687

Penteado, T. C. Z. \& Guzzo, R. S. L. (2010). Educação e Psicologia: a construção de um projeto político-pedagógico emancipador. Psicologia \& Sociedade, 22 (3), 569-577. https://www.scielo.br/j/psoc/a/ZrdyvKxZdYhCqXqZ9X7GMVN/?format=pdf\&lang=pt

Rocha, F. S. M., Loss, T., Almeida, B. L. C., Motta, M. S. \& Kalinke, M. A. (2020). O Uso de Tecnologias Digitais no Processo de Ensino durante a Pandemia da CoViD-19. Interacções, 16 (55), 58-82. https://doi.org/10.25755/int.20703

Rondini, C. A., Pedro, K. M. \& Duarte, C. S. (2020). Pandemia do Covid-19 e o ensino remoto emergencial: Mudanças na práxis docente. Interfaces CientíficasEducação, 10 (1), 41-57. https://doi.org/10.17564/2316-3828.2020v10n1p41-57

Schimiguel, J., Fernandes, M. E. \& Okano, M. T. (2020). Investigando aulas remotas e ao vivo através de ferramentas colaborativas em período de quarentena e Covid-19: relato de experiência. Research, Society and Development, 9 (9), e654997387-e654997387. https://doi.org/10.33448/rsd-v9i9.7387

Schneider, E. M., Fujii, R. A. X \& Corazza, M. J. (2017). Pesquisas quali-quantitativas: contribuições para a pesquisa em ensino de ciências. Revista Pesquisa Qualitativa, 5 (9), 569-584. https://editora.sepq.org.br/rpq/article/view/157/100

Silva, A. J. N. (2010). Educação: agregando, incluindo e almejando oportunidades. (4a ed.),, Atena Editora, Ponta Grossa. 10.22533/at.ed.153202309

Souza, K. R. \& Kerbauy, M. T. M. (2017). Abordagem quanti-qualitativa: superação da dicotomia quantitativa-qualitativa na pesquisa em educação. Educação e Filosofia, 31 (61), 21-44. https://doi.org/10.14393/REVEDFIL.issn.0102-6801.v31n61a2017-p21a44

Stevanim, L. F. (2020). Exclusão nada remota: desigualdades sociais e digitais dificultam a garantia do direito à educação na pandemia. Radis: Comunicação e Saúde, (215), 10-15. https://www.arca.fiocruz.br/bitstream/icict/43180/2/Exclus\%c3\%a3oNadaRemota.pdf 